\title{
Surgical outcomes for colon and rectal cancer over a decade: results from a consecutive monocentric experience in 902 unselected patients
}

\author{
Bruno Andreoni*1, Antonio Chiappa ${ }^{1}$, Emilio Bertani ${ }^{1}$, Massimo Bellomi2, \\ Roberto Orecchia ${ }^{3}$, MariaGiulia Zampino ${ }^{4}$, Nicola Fazio ${ }^{4}$, Marco Venturino ${ }^{5}$, \\ Franco Orsi ${ }^{2}$, Angelica Sonzogni ${ }^{6}$, Ugo Pace $^{1}$ and Lorenzo Monfardini ${ }^{2}$
}

Address: ${ }^{1}$ Dept. of General Surgery, European Institute of Oncology, University of Milano, Italy, ${ }^{2}$ Division of Radiology, European Institute of Oncology, University of Milano, Italy, ${ }^{3}$ Division of Radiotherapy, European Institute of Oncology, University of Milano, Italy, ${ }^{4}$ Division of Oncology, European Institute of Oncology, Milano, Italy, ${ }^{5}$ Division of Anaesthesiology, European Institute of Oncology, Milano, Italy and ${ }^{6}$ Division of Pathology, European Institute of Oncology, Milano, Italy

Email: Bruno Andreoni* - bruno.andreoni@ieo.it; Antonio Chiappa - antonio.chiappa@unimi.it; Emilio Bertani - emilio.bertani@ieo.it; Massimo Bellomi - massimo.bellomi@ieo.it; Roberto Orecchia - roberto.orecchia@ieo.it; MariaGiulia Zampino - maria.zampino@ieo.it; Nicola Fazio - nicola.fazio@ieo.it; Marco Venturino - marco.venturino@ieo.it; Franco Orsi - franco.orsi@ieo.it;

Angelica Sonzogni - angelica.sonzogni@ieo.it; Ugo Pace - ugo.pace@ieo.it; Lorenzo Monfardini - lorenzo.monfardini@ieo.it

* Corresponding author

Published: 4 July 2007

World Journal of Surgical Oncology 2007, 5:73 doi:10.1 186/1477-7819-5-73
Received: 2 March 2007

Accepted: 4 July 2007

This article is available from: http://www.wjso.com/content/5/l/73

(c) 2007 Andreoni et al; licensee BioMed Central Ltd.

This is an Open Access article distributed under the terms of the Creative Commons Attribution License (http://creativecommons.org/licenses/by/2.0), which permits unrestricted use, distribution, and reproduction in any medium, provided the original work is properly cited.

\begin{abstract}
Background: This study evaluates the surgical morbidity and long-term outcome of colorectal cancer surgery in an unselected group of patients treated over the period 1994-2003.

Methods: A consecutive series of 902 primary colorectal cancer patients (489 M, 4I3 F; mean age: 63 years \pm II years, range: 24-88 years) was evaluated and prospectively followed in a university hospital (mean follow-up $36 \pm 24$ months; range: 3-I08 months). Perioperative mortality, morbidity, overall survival, curative resection rates, recurrence rates were analysed.

Results: Of the total, 476 colorectal cancers were localized to the colon (CC, 53\%), 406 to the rectum (RC, $45 \%)$, 12 (I\%) were multicentric, and 8 were identified as part of HNPCC (1\%). Combining all tumours, there were 186 cancers $(20.6 \%)$ defined as UICC stage I, 235 (26.1\%) stage II, 270 (29.9\%) stage III and I87 (20.6\%) stage IV cases. Twenty-four (2.7\%) cases were of undetermined stage. Postoperative complications occurred in $38 \%$ of the total group $(37.8 \%$ of CC cases, $37.2 \%$ of the RC group, $66.7 \%$ of the synchronous cancer patients and $50 \%$ of those with HNPCC, $p=0.19)$ Mortality rate was $0.8 \%,(1.3 \%$ for colon cancer, $0 \%$ for rectal cancer; $p=0.023$ ). Multivisceral resection was performed in $14.3 \%$ of cases. Disease-free survival in cases resected for cure was $73 \%$ at 5 -years and $72 \%$ at 8 years. The 5 - and 8 -year overall survival rates were $71 \%$ and $61 \%$ respectively (total cases). At 5 -year analysis, overall survival rates are $97 \%$ for stage I disease, $87 \%$ for stage II, $73 \%$ for stage III and $22 \%$ for stage IV respectively $(\mathrm{p}<0.000 \mathrm{I})$. The 5 -year overall survival rates showed a marked difference in R0, RI+R2 and non resected patients $(82 \%, 35 \%$ and $0 \%$ respectively, $\mathrm{p}<0.000 \mathrm{I})$. On multivariate analysis, resection for cure and stage at presentation but not tumour site (colon vs. rectum) were independent variables for overall survival $(p<0.000 \mathrm{I})$.
\end{abstract}

Conclusion: A prospective, uniform follow-up policy used in a single institution over the last decade provides evidence of quality assurance in colorectal cancer surgery with high rates of resection for cure where only stage at presentation functions as an independent variable for cancer-related outcome. 


\section{Background}

Although colorectal cancer (CRC) must be seen as a tumour biological entity, the prognosis for colon cancer and rectal cancer individually differs considerably. The most important reason is certainly the great difference in loco-regional tumour failure, which is significantly higher for rectal cancer. In addition, adjuvant therapy regimens for colon cancer and rectal cancer as well as neoadjuvant radio/chemotherapy in selected patients with rectal cancer differ substantially. Based on the International Union Against Cancer (UICC)/American Joint Committee on Cancer (AJCC) tumour staging system [1-5], complete tumour removal (R0 resection) [1-7], is essential for local tumour control and long term survival.

The aim of this study was to review a large consecutive series of colorectal cancer patients prospectively followed between 1994 and2003. Morbidity and long-term survival after colorectal cancer surgery in relation to stage and radicality as well as after multivisceral resection, were analysed.

\section{Methods \\ Patients}

Between January 1994 and December 2003, a total of 902 patients were treated for primary colonic or rectal cancer. Patients' median age was $63 \pm 11$ years (range 24-88 years). There were 489 men and 413 women. Tumours were classified as rectal when adenocarcinomas were located within $12 \mathrm{~cm}$ above the anal verge with rigid proctoscopy. Multicentric colorectal cancers were staged according to the most advanced of the tumours.

Data concerning clinico-pathological staging and postoperative course were collected prospectively using a hospital tracking system based on ICD-coding for colorectal cancer with all Histologically confirmed cases were included. Eight hundred and seventy-three patients (96.8\%) underwent elective surgery after mechanical bowel preparation using phosphates in $4 \mathrm{~L}$ of water, 29 patients $(3.2 \%)$ were submitted to emergency surgery without any bowel preparation. Among these there were 14 patients $(1.6 \%)$ presenting with secondary large bowel perforation, $12(1.3 \%)$ with obstructing tumour and 3 $(0.3 \%)$ with actively bleeding rectal cancer.

\section{Preoperative staging}

Preoperative staging was performed by abdominal ultrasound, thoraco-abdominal CT scan, abdominal magnetic resonance imaging and endoscopic ultrasound as single modalities or in combination depending on their availability and the surgeon's preference. All patients had at least one form of preoperative imaging for staging purposes.

\section{Surgical procedure}

Tumour resections were performed en bloc after ligation of the segmental vessels, followed by lymph node dissection. Anastomoses were established by stapling devices, usually performed in an end-to-end fashion for left, transverse and rectal resections and were termino-lateral for right colon resections. In selected cases we performed anastomoses according to Knight-Griffen's technique [8]. Staplers were routinely used. Coloanal anastomoses were performed usually combined with a protective loop ileostomy.

Standard resections were defined as tumour resections including standard lymph dissections restricted to the tumour-bearing bowel section. Multivisceral resections were defined as "organs or structures adherent to the tumour with a need for en bloc removal to obtain a curative situation". These multivisceral resections were classified according to the organ site (genitourinary system, liver, small bowel) or as "various" (i.e.: abdominal wall, large bowel). All operations were performed by the same surgical team (BA, RB, AC, FL, SP, UP, EB); each of whom had undergone postgraduate specialist training in colorectal surgery.

Peroperative morbidity and mortality were registered following 30 days after surgery.

\section{Pathology}

Tumours were staged histopathologically and clinically according to the TNM/Dukes/UICC system [9].

The radicality of the surgical procedure performed was classified as "curative" (R0, no tumour left behind microscopically at resection margins); "questionably curative" (R1, tumour left behind microscopically at resection margins, or any other "Gray zone" situation that would question a curative operation, such as suspect but unproven metastases); "palliative" (R2, macroscopical tumour left behind); or "unresectable" [4].

\section{Adjuvant/neo-adjuvant treatments}

Rectal cancer patients with locally advanced tumours (T3, T4, or N positive) defined by preoperative staging investigations, received bifractionated accelerated radiotherapy for a maximum of $41.6 \mathrm{~Gy}$ or conventional radiotherapy for a total of 50.4 Gy and concomitant chemotherapy (within clinical studies with regimens containing 5-fluorouracil, folinic acid, oxaliplatin, methotrexate or raltitrexed). Patients who did not receive neoadjuvant therapies with a pathological staging pT3-4 N0 and pT1N1-2 cases received postoperative radio-chemotherapy. For patients undergoing Mayo Clinic [10] or Machover regimens [11] for 6 cycles "sandwich" schedules were used ( 2 cycles $\mathrm{CT} \rightarrow \mathrm{RT} \rightarrow 4$ cycles CT). Patients with a central 
venous system underwent continuous infusion chemotherapy with 5-FU concomitant with radiotherapy. The treatment will last for 4-6 months. Chemotherapy regimens as described were employed in an adjuvant setting for patients who underwent preoperative bifractionated radiotherapy or for $\mathrm{C}$ and $\mathrm{D}$ colon cancer patients. UICC stage T3NO colon cancer patients were candidate for the same chemotherapy regimens according to the presence of risk factors such as dedifferentiated tumour or vascular invasion after counselling with medical oncologist.

The indication for additional treatment was assessed either adjuvantly in curatively resected lesions in lymph node-positive stages, or palliatively-resected cases for stage IV or unresectable lesions. Liver or lung metastases were resected if, an R0 situation was expected after resection. If in fact an R0 situation was obtained, these patients were classified as R0 patients; otherwise they were R1 or R2. Metastases were resected in 32 of 188 UICC stage IV patients $(17 \%)$ with synchronous liver metastses and without additional metastatic spread. Of all 902 patients, $560(62.1 \%)$ underwent additional treatment: chemotherapy in $438(48.6 \%)$, radiotherapy in $4(1 \%)$ and radio-chemotherapy in $118(13.1 \%)$ mainly for stage II or III rectal cancer (111/122 patients, $91 \%$, who underwent postoperative radiotherapy). Eighty-four patients affected by rectal cancer underwent neoadjuvant radiotherapy, in 36 of them (75\%) associated with chemotherapy.

\section{Follow-up}

Patients were followed after curative resction using a follow-up program. This program consisted of three appointments per year (years 1-3), two appointments per year (years 4-5), and yearly appointments (years 6-10). All appointments included clinical evaluation, carcinoembryonic antigen (CEA) serum test, faecal blood test, abdominal ultrasonography (months $8,20,30,42$, and 54), chest radiography (months 12, 24, 36, 48, and 60), colonoscopy or double-contrast enema (months 12, 24, 48), rectal endoscopy (months 12, 24, 48), computed tomography (CT) (months 4, 16, 30, 42, and 54), and MRI where appropriate. When loco-regional recurrence was suspected, positron emission tomography (PET) scanning was used if available. Loco-regional recurrence was defined as histologically- or radiologically-proven disease presenting within the field of previous surgery. Thirty-two patients (3.5\%) were lost to follow-up. Mean length of follow-up for 870 patients was 42 month (range 6-108).

\section{Statistics}

Analysis was performed using a statistical software package (SPSS, Chicago, IL advanced model statistical package). Comparison of variables was performed with the Chi-square test and the Student's t-test for categorical and continuous variables, respectively. Actuarial local recurrence and survival were analysed using the Kaplan-Meier method with comparisons between groups being made with the log-rank test. Multivariate analysis was performed using the Cox proportional Hazard model where p values $<0.05$ were considered to be significant.

\section{Results \\ Operative findings}

A total of 902 patients with colorectal cancer were included in the analysis. Among the lesions, 476 (53\%) were localized in the colon, $406(45 \%)$ in the rectum, 12 $(1 \%)$ were multicentric and $8(1 \%)$ were identify as a part of HNPCC. Surgical procedures are listed in Table 1. Among these, there were 12 patients whose tumour was excised transanally, 7 patients submitted to low anterior resection or Miles operation who showed a complete response to neoadjuvant RT-CT. Palliative treatment was undertaken in $21.6 \%$ (196 of the patients), and consisted mainly of tumour resection in patients with metastases. The tumour was unresectable in 3\% (27 of patients) in

Table I: Type of surgical procedures performed in 902 patients affected by colorectal cancer

\begin{tabular}{|c|c|c|c|c|}
\hline & COLON N(\%) & RECTUM N(\%) & MULTICENTRIC N(\%) & HNPCC N(\%) \\
\hline Anterior resection of rectum & - & 304 & - & - \\
\hline Right colectomy & $201(42.3)$ & - & - & - \\
\hline Left colectomy & $167(35.0)$ & - & - & - \\
\hline Segmental resection & $79(16.7)$ & - & - & $6(75.0)$ \\
\hline Abdomino-perineal resection & - & $73(18.0)$ & - & - \\
\hline Subtotal colectomy & $6(1.2)$ & - & II (9I.7) & $2(25.0)$ \\
\hline Hartmann resection & $8(1.7)$ & $6(1.5)$ & - & - \\
\hline Diversion colostomy & $3(0.6)$ & II (2.7) & - & - \\
\hline Transanal excision & - & $12(2.9)$ & - & - \\
\hline Colonic by-pass & $10(2.1)$ & - & - & - \\
\hline Explorative laparotomy & $2(0.4)$ & - & $\mathrm{I}(8.3)$ & - \\
\hline Total & $476(100)$ & $406(100)$ & $12(100)$ & $8(100)$ \\
\hline
\end{tabular}


whom colostomy or intestinal by-pass was the preferred procedure. Among these, there were 5 patients affected by unresectable colon cancer without distant metastases who underwent diversion colostomy or intestinal by-pass Multivisceral resections were performed in $14.3 \%$ of the patients (129/902). The single organ-sites mainly involved in multivisceral resections were the genitourinary system $(9.4 \%)$, and the small bowel $(0.9 \%)$.

Mean intraoperative blood loss was $300 \pm 267 \mathrm{~mL}$ (range $100-2200 \mathrm{~mL}$ ) and rectal cancer surgery was significantly associated with increased intraoperative bleeding $(212 \pm$ 187 vs $376 \pm 308$ mean blood loss for colonic vs rectal resections respectively; $\mathrm{p}=0.02)$. Sixteen patients were intraoperatively transfused (1.8\%) with a mean of $1046 \pm$ $867 \mathrm{~mL}$ of packed red blood cells (range $500-3000 \mathrm{~mL}$ ).

\section{Pathology}

The stage distribution of the tumours treated is shown in Table 2. Colon tumours were mainly UICC stages II, III or IV $(83.1 \%)$, and rectal tumours were of stages I, II or III $(86.2 \%)$. Tumour stage was not determined for $24(2.7 \%)$ of all tumours. The radicality of the surgical procedure is shown in Table 3. The rate of R0 resections was $77.4 \%$ (n $=699)$ for all patients, $73 \%(347 / 476)$ for colon cancer, $84.7 \%$ (344/406) for rectal cancer, and $66.7 \%$ (8/12) for multicentric colorectal cancer ( $p<0.0001)$. "Questionably curative" situations, including $\mathrm{R} 1$ resections or any other situation that left doubt about the intended curative character of the surgical procedure, occurred in $0.8 \%$ ( 7 of all patients). In 107 out of 129 patients (82.9\%) undergoing multivisceral resection, an R0 situation was obtained.

\section{Morbidity and mortality}

Morbidity (Table 4) was documented in $38 \%$ of all patients (343/902), 37.8\% (180/476) of colon cancer patients, $37.2 \%(151 / 406)$ of rectal cancer patients, $50 \%$ (4/8) of HNPCC, and $66.7 \%$ (8/12) of multicentric colorectal cancer patients $(\mathrm{p}=0.19)$. The mean intraoperative blood loss for patients who developed or not postoperative complications was $388 \pm 384$ vs $254 \pm 164$ respectively ( $\mathrm{p}=0.018$ ). The rates of anastomotic leakage were $7 \%$ in all 778 patients who had an anastomosis, 5.5\% (26/456) for colon patients, $10.4 \%$ (33/305) for rectum patients, $\mathrm{p}=0.01$. Wound infections occurred in rectal cancer patients with a frequency of $20 \%(81 / 406)$ and in those with colon cancer in $19.3 \%$ (92/476). Complications were observed equally often in standard and multivisceral resections $(37.5 \%$ vs. $41.1 \%, \mathrm{p}=0.44)$. Nineteen patients required reoperation (13 for anastomotic leakage; 2 for small bowel obstruction; 3 for wound dehiscence, and 1 for mesenteric ischemia). Reoperation was slightly more frequent after colonic $(2.7 \% ; 13 / 476)$ than rectal resection $(1.2 \% ; 5 / 406)(\mathrm{p}=0.12)$, and after multivisceral than standard resection $(3.1 \% ; 4 / 129$ vs. $1.9 \%$; $15 / 773)(p=0.4)$. The incidence of perioperative blood transfusions was $10.9 \%$ (98 patients who received a mean of $857 \pm 792 \mathrm{~mL}$ of packed red blood cells) with no significant difference between colon and rectal cancer patients (43/476, $9 \%$ for colon $v s$. 52/406, $12.8 \%$ for rectum; $\mathrm{p}=$ 0.072 ). Patients who underwent multivisceral resection were more likely to be transfused $(21 / 129,16.3 \%$ vs. $77 /$ $773,10 \% ; \mathrm{p}=0.03)$. The overall complication rate was associated to perioperative blood transfusions (284/804 patients having complications, $35.3 \%$, among non transfused $v$ s. 59/98, 60.2\% among transfused patients; $\mathrm{p}<$ $0.0001)$.

The 30-day mortality rate was $0.8 \%(7 / 902)$ for all patients. Mortality was $1.3 \%$ for colon cancer ( 6 patients), and $0 \%$ for rectal cancer $(\mathrm{p}=0.023)$. There was no difference in the mortality rate between standard and multivisceral resections $(0.6 \%, 5 / 773$ vs. $1.6 \%, 2 / 129) ; p=0.28)$. Peroperative mortality rate was significantly correlated with the radicality of the surgical procedure where $0.1 \%$ mortality rate (1 patient) was noted for R0 resections, $2.8 \%$ (5 patients) for $\mathrm{R} 1+\mathrm{R} 2$ resections and 3.8\% (1 patient) for unresected patients $(\mathrm{p}<0.0001)$.

\section{Tumour recurrence}

Patterns of recurrence are represented in table 5. Distant recurrence was the main focus of recurrence both in colon and in rectal cancer. However, local recurrence was significantly more common in rectal cancer patients, associated or not with distant recurrence in $6.1 \%(29 / 476)$ colon; $14.0 \%,(57 / 476)$ rectum $(\mathrm{p}<000.1)$. The total rate of distant metastases into the liver or lungs were resected whenever possible; otherwise they were treated systematically or regionally (liver).

Table 2: UICC tumour stage according to site of primary tumour. Mainly, there were more rectal cancers in UICC stage $I$ and colon cancers in UICC stage IV $(p<0.0001)$.

\begin{tabular}{lcccccc}
\hline & UICC I & UICC II & UICC III & UICC IV & Undetermined & Total \\
\hline Colon cancer & $80(16.8)$ & $13 I(27.5)$ & $130(27.3)$ & $132(27.7)$ & $3(0.6)$ & $476(100)$ \\
Rectal cancer & $97(23.9)$ & $99(24.4)$ & $136(33.5)$ & $53(13.1)$ & $21(5.2)$ & $406(100)$ \\
HNPCC* & $8(100)$ & 0 & 0 & 0 & 0 & $8(100)$ \\
Multicentric & $I(8.3)$ & $4(33.3)$ & $4(33.3)$ & $3(25)$ & 0 & $12(100)$ \\
\hline
\end{tabular}

*HNPCC: hereditary non polyposis colorectal cancer 
Table 3: Surgical radicality according to site of primary tumour. Mainly, there were more rectal cancer patients undergoing R0 resection than colon cancer patients $(p<0.0001)$.

\begin{tabular}{lcccc}
\hline & RO resection & RI+R2 resection & Non resected & Total \\
\hline Colon cancer & $339(71.2)$ & $121(25.4)$ & $16(3.4)$ & $476(100)$ \\
Rectal cancer & $344(84.7)$ & $53(13.1)$ & $9(2.2)$ & $406(100)$ \\
HNPCC* & $8(100)$ & $3(25)$ & $1(8.3)$ & $8(100)$ \\
Multicentric & $8(66.7)$ & 0 & $12(100)$ \\
\hline
\end{tabular}

*HNPCC: hereditary non polyposis colorectal cancer

Disease-free survival rate for the 699 R0 patients was $73 \%$ and $72 \%$ at 5 and 8 years respectively and was significantly influenced by the site of the tumour where 5-year disease-free survival rates for colon, rectum and multicentric tumours were $78 \%, 68 \%$ and $24 \%$ respectively ( $\mathrm{p}<$ 0.0001).

\section{Overall survival rates}

Five- and 8-years overall survival rates were $71 \%$ and $61 \%$ respectively (total cases) and were significantly dependent on tumour stage (Figure 1).

We decided to perform an univariate analysis on overall survival assessing UICC tumour stage, tumour site (colon vs. rectum vs. multicentric), sex, age ( $>$ or $<65$ years), adjuvant or neoadjuvant treatments, radicality of surgery (R0 vs. R1 vs. R2), postoperative anastomotic leak, perioperative blood transfusions.

For all patients, 5-year survival rates were 97\% (UICC I), $87 \%$ (UICC II), 73\% (UICC III), and 22\% (UICC IV), differing significantly $(p<0.0001)$. The $\mathrm{T}, \mathrm{N}$, and M categories significantly influenced survival. Five-year survival rates for $\mathrm{T} 1, \mathrm{~T} 2, \mathrm{~T} 3$ and $\mathrm{T} 4$ cases were respectively $96 \%$, $87 \%, 73 \%$ and $45 \%(\mathrm{p}<0.0001)$. N0 significantly differed from any other $\mathrm{N}$ category, where 5-year survival rates for N0, N1 and N2 patients were 86\%, 67\% and 43\% respectively $(\mathrm{p}<0.0001)$ (log-rank test).
Overall 5 -year survival rates for patients affected by colon, rectal, or multicentric tumour were 69 vs. 73 vs. 63 respectively $(p=0.061)$. Neither sex or age $>65$ year affected overall survival ( $\mathrm{p}=0.72$ and $\mathrm{p}=0.12$ respectively), nor did the occurrence of an anastomotic leak, $(\mathrm{p}=0.85)$.

For colon cancer (Figure 2a), the 5-year survival rates were 100\% (UICC I), 91\% (UICC II), 76\% (UICC III), and $16 \%$ (UICC IV). In the group of UICC T3NO colon-cancer patients we registered a slight but not significant better survival $(92 \%$ vs. $80 \%$ at 5 years; $p=0.58)$ among those who underwent adjuvant chemotherapy.

Rectal cancers (Figure 2b) showed 5-year survival rates of 93\% (I), 83\% (II), 68\% (III), 36\% (IV), with significant differences $(\mathrm{p}<0.0001)$. Rectal cancer patients undergoing neoadjuvant radiotherapy had a similar overall survival in comparison to patients undergoing postoperative radiotherapy ( $82 \%$ vs. $78 \%$ respectively; $\mathrm{p}=0.13$ ).

The 5-year overall survival showed a marked difference in $\mathrm{R} 0, \mathrm{R} 1+\mathrm{R} 2$ resection patients and unresected patients with a survival of $82 \%, 35 \%$ and $0 \%$ respectively, where a significant difference was noted between $\mathrm{R} 0$ vs $\mathrm{R} 1+\mathrm{R} 2$ cases $(p<0.0001)$ and $R 1+R 2$ vs. unresected cases $(p=0.0009)$ (Figure 3 ). The influence of any subsequent adjuvant, first line or palliative treatment was not analysed in detail and consisted of heterogeneous groups.

Table 4: Complications following surgery according to site of primary tumour. Anastomotic dehiscence were more common after anterior resection of rectum than after surgery for colonic cancer.

\begin{tabular}{|c|c|c|c|c|c|}
\hline & Colon cancer & Rectal cancer & HNPCC* & Multicentric & $p$ \\
\hline Overall complications & $180 / 476(37.8)$ & $15 \mid / 406(37.2)$ & $4 / 8(50)$ & $8 / 12(66.7)$ & 0.19 \\
\hline Postoperative haemoperitoneum & $3 / 476(0.4)$ & $2 / 406(0.5)$ & 0 & 0 & 0.98 \\
\hline Anastomotic dehiscence & $26 / 456(5.5)$ & $33 / 305(10.4)$ & $2 / 8(25)$ & 0 & 0.01 \\
\hline Abdominal abscess & $17 / 476(3.6)$ & $6 / 406(1.5)$ & 0 & $2 / 12(16.7)$ & 0.006 \\
\hline Wound complications & $92 / 476(19.3)$ & $81 / 406(20)$ & $3 / 8(37.5)$ & $4 / 12(37.6)$ & 0.39 \\
\hline Pneumonia & $16 / 476(3.4)$ & $4 / 406(I)$ & 0 & $4 / 12(37.3)$ & 0.025 \\
\hline Ileus & $7 / 476(1.5)$ & $2 / 406(0.5)$ & 0 & $1 / 12(8.3)$ & $0.05 I$ \\
\hline Urinary tract infection & $8 / 476(1.7)$ & $15 / 406(3.7)$ & 0 & $1 / 12(8.3)$ & 0.16 \\
\hline CVC§̧infection & $19 / 476(4.0)$ & $17 / 406(4.2)$ & 0 & $1 / 12(8.3)$ & 0.82 \\
\hline Cardiovascular & $9 / 476(1.9)$ & $5 / 406(1.2)$ & 0 & $2 / 12(16.7)$ & 0.001 \\
\hline Others minor medical complications & $8 / 476(1.7)$ & $8 / 406(2.0)$ & 0 & 0 & 0.92 \\
\hline
\end{tabular}


Table 5: Patterns of recurrence in 698 patients undergoing R0 resection for colorectal cancer according to site of primary tumour. Local recurrence were significantly more common in rectal cancer patients $(p<0.0001)$.

\begin{tabular}{lcccc}
\hline & Local recurrence & Local+distant recurrence & Distant recurrence & Total \\
\hline Colon cancer & $18(5.2)$ & $1 \mathrm{I}(3.2)$ & $125(36.1)$ & $346(100)$ \\
Rectal cancer & 3710.8 & $20(5.8)$ & $56(16.3)$ & $344(100)$ \\
Multicentric & $2(25)$ & $1(12.5)$ & $4(50)$ & $8(100)$ \\
\hline
\end{tabular}

Perioperative blood transfusions didn't influence overall survival $(71 \%$ and $63 \%$ at 5 and 8 years for transfused $v$ s. $73 \%$ and $51 \%$ for transfused patients respectively; $\mathrm{p}=$ $0.68)$.

\section{Multivariate analysis}

Factors significant on univariate analysis were matched in a multivariate analysis on overall survival assessing UICC tumour stage, radicality of surgical procedure, and tumour site, where only surgical radicality and UICC tumour stage were associated with outcome (Table 6).

\section{Discussion}

The present study showed that a uniform policy of treatment could provide exceptionally low postoperative mortality rates $(0.8 \%)$ and excellent results in terms of longterm survival rate $(71 \%$ at 5 years) in an unselected and consecutive series of colorectal cancer patients who under-

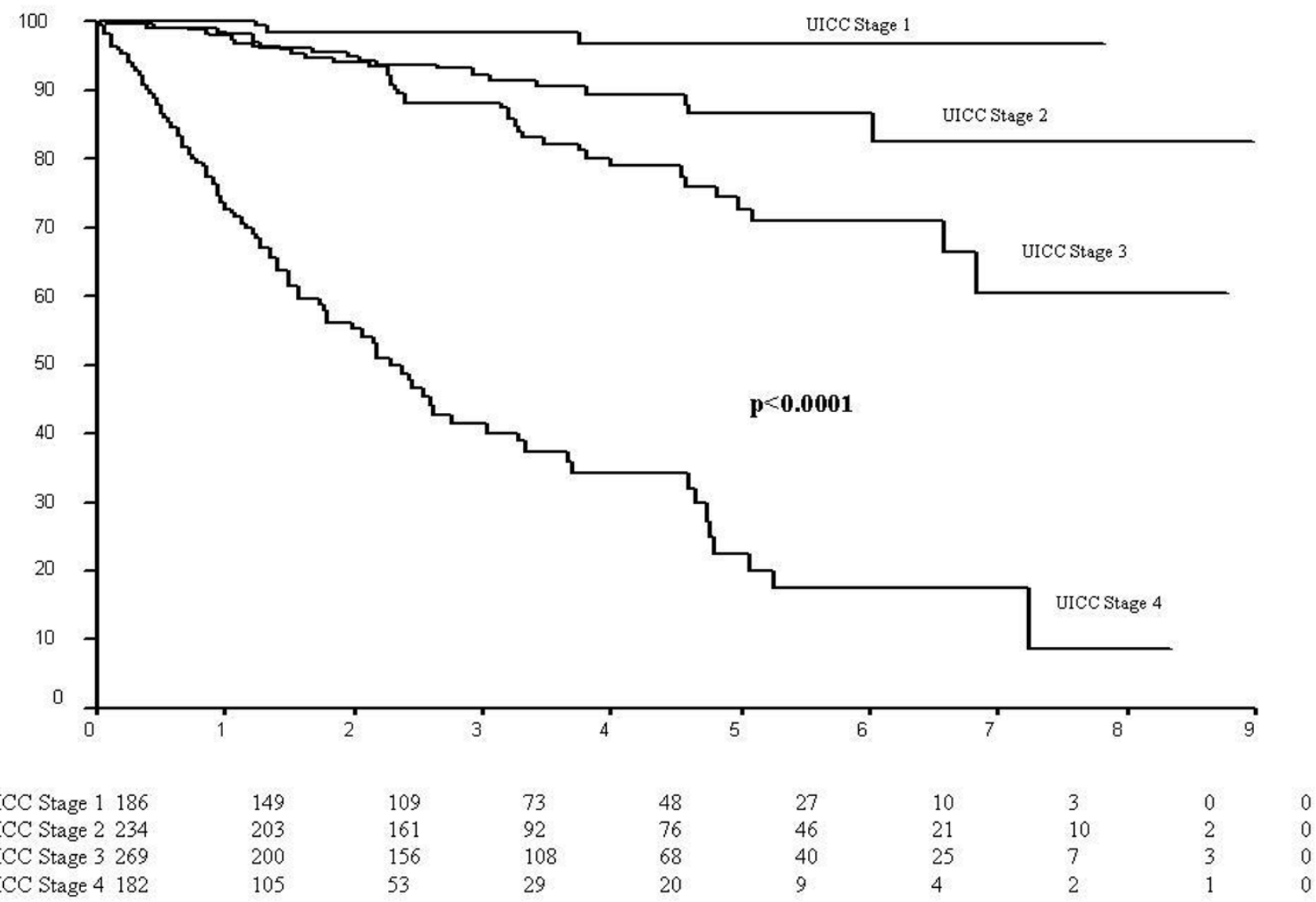

Figure I

Survival according to UICC tumour stage ( 7 patients who died peroperatively were excluded from the analysis). 

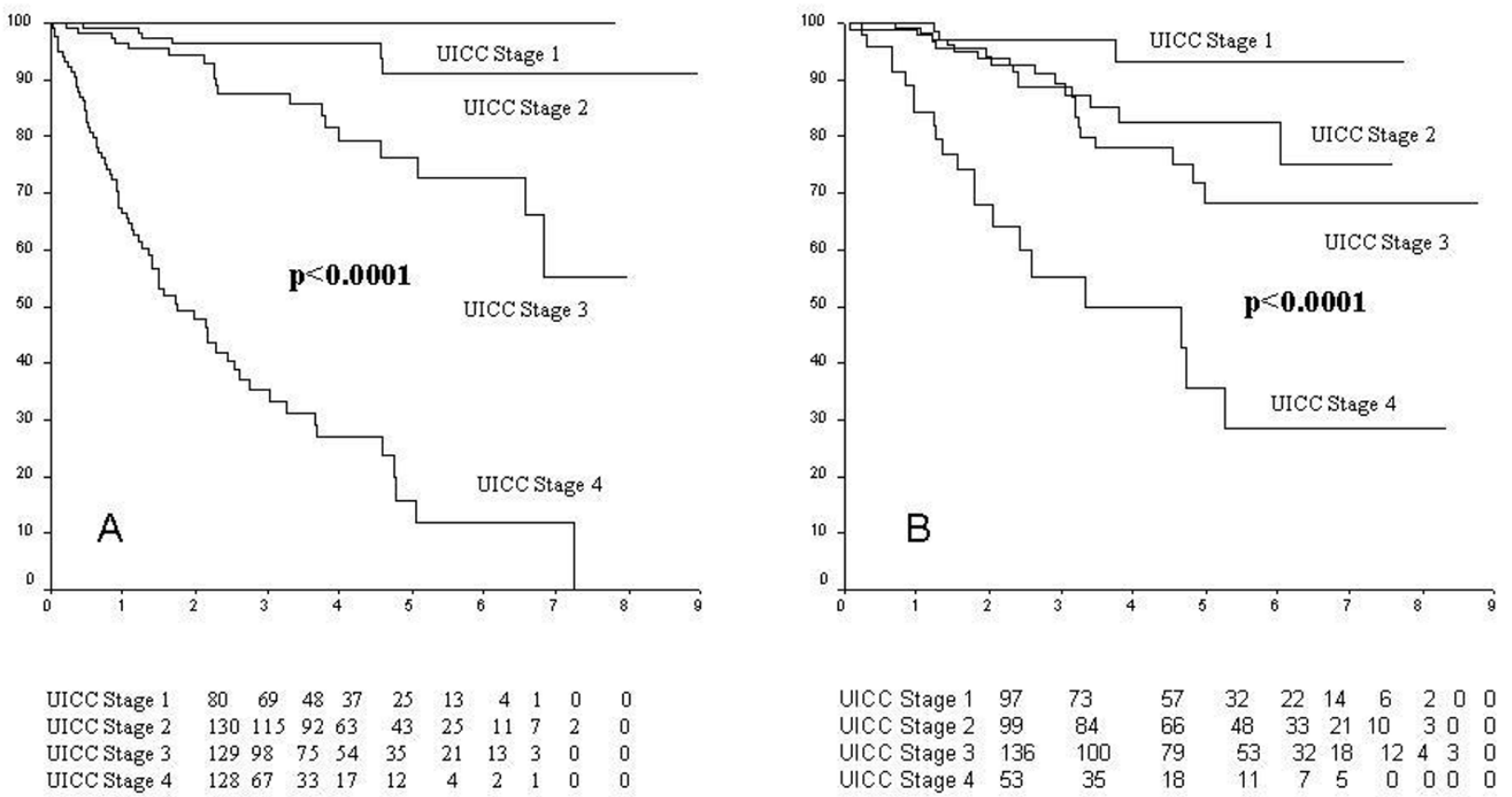

Figure 2

(a) Survival according to UICC tumour stage for colon cancer patients undergoing surgery. (b) Survival according to UICC tumour stage for rectal cancer patients undergoing surgery.

went surgery. The ability to remove the primary tumour also in presence of adjacent organ infiltration was one of the main cause of success in our series.

Most colorectal cancers referred to surgical units can be resected, as seen by our overall tumour-resection rate of $97 \%$. This seems remarkable because the prognosis for patients with unresectable tumours was even worse than after palliative resection. However, the institutional resection rate is influenced by both the surgeon and patient factors and can therefore never be taken absolutely or be regarded as a quality-control parameter.

The group of patients with synchronous multicentric colorectal cancer (in our series 1\%), is usually not referred to in reports of colorectal-treatment outcome [12] , whereas metachronous colorectal cancer occurs in $0.5 \%$ to $4.0 \%$ of cases $[13,14]$. The reported rate of synchronous multicentric colorectal cancer is $2 \%$ to $10 \%$ and occurs in older patients, mainly in the sigmoid loop and in 30\% of cases in nonadjacent colon segments [15]. Synchronous colorectal cancers are usually classified according to site with most advanced-stage tumour and do not show any prognostic differences compared to single-site tumours. However, their existence supports the need for complete staging with total colonoscopy and biopsy of all suspected lesions preoperatively. If total preoperatively colonoscopy cannot be performed, it should be done not later than 3 months postoperatively. Whenever possible, endoscopic polypectomy should be performed prior to surgery.

We registered a morbidity of $38 \%$, and a mortality of $0,8 \%$ during the past 9 years of CRC surgery. The apparently high incidence of postoperative overall complication rate may be due to the accurate monitoring and registration of late complications as suggested by others [16]. Conversely, the perioperative mortality figure is quite low in comparison to those reported in literature for elective operations [17]. A possible explanation is that, as recently demonstrated by Billingsley et al. [18], very high surgeon volumes are associated with a reduction in surgical complications. However, the association between increasing hospital volumes and postoperative mortality appears to derive mainly from a full spectrum of clinical services that may facilitate the prompt recognition and treatment of complications. Our findings led us to conclude that although increasing surgeon volumes may decrease complications, decreasing complications is not the major mechanism by which practice volumes decrease postoperative mortality. In fact, minimizing postoperative mortality is associated primarily with systems that provide increased safety in the postoperative period. Our reported $7 \%$ rate of anastomotic leakage (5,5\% colon, $10,4 \%$ rectum) is within the reported range [19]. We prefer stapled 


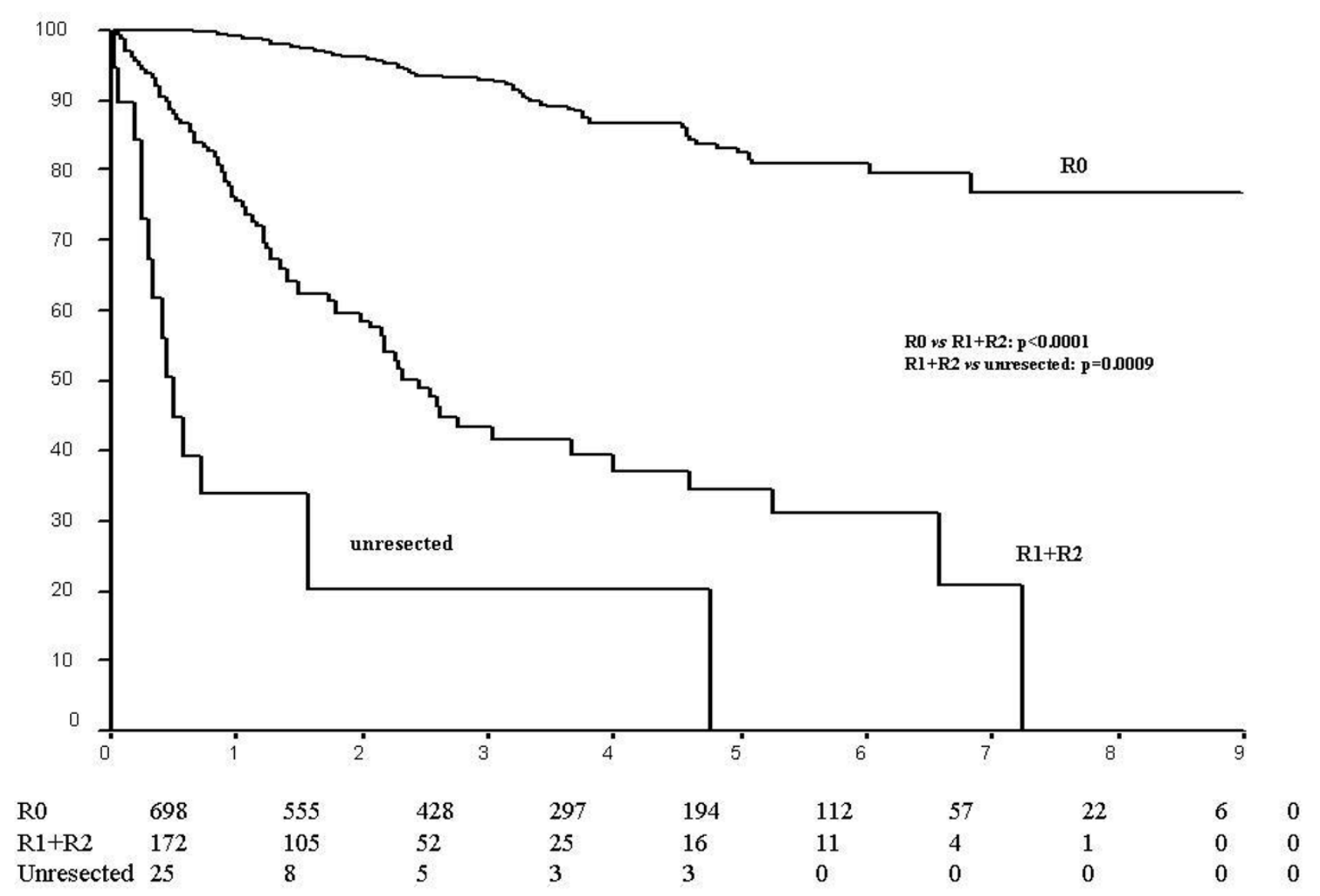

Figure 3

Survival according to radicality of surgery.

anastomoses. Some authors reported a strong relationship between postoperative anastomotic leakage and longterm survival [20]. These findings were not confirmed by our study.

Long-term survival after resection of CRC depends on tumour stage and radicality of the surgical procedure. We observed overall 5-year survival rates of $82 \%$ (R0), 35\% $(\mathrm{R} 1+\mathrm{R} 2), 0 \%$ (unresectable) in CRC patients. Others

Table 6: Multivariate analysis on overall survival for colorectal cancer patients undergoing surgery according to different variables.

\begin{tabular}{lccc}
\hline & Hazard ratio & $95 \%$ I. C. $\S$ & p \\
\hline Surgical radicality* & 3.000 & $2.247-4.007$ & $<0.0001$ \\
UICC tumour stage & 1.972 & $1.569-2.477$ & $<0.000$ I \\
Tumour site\# & 0.851 & $0.637-1.137$ & $\mathbf{0 . 2 7 4}$ \\
\hline
\end{tabular}

§l. C.: confidence interval

*R0 vs RI+R2 vs unresected patients

\#Colon vs rectum vs multicentric cancer reported similar results $[19,21-24]$. Therefore, the main aim of any surgical procedure is to obtain an R0 resection and to circumvent unresectability even if multivisceral resections are necessary. Multivisceral resections were performed in $14,3 \%$ of our patients. This slightly higher rate compared to other reported rates [25-27], is explained by the relatively high number of rectal cancer patients in our Division. Survival rates similar to those for standard resections were observed with multivisceral resections, as in other reports [27-29], so long as R0 resections resulted. However, in contrast to others [30], we have also seen an indication for multivisceral primary tumour removal when resectable hepatic metastases were found or in patients who were suitable to undergo neoaadjuvant chemotherapy. The prognosis of patients with resectable liver metastases is potentially curative, we observed response rate in 10 patients out of 27 who underwent neoadjuvant chemotherapy for liver metastses from CRC (unpublished data). In these selected patients we observed a 5-year survival rate of $64 \%$ following hepatic surgery. 
Local tumour recurrence is significantly influenced by surgical technique but occurred in only $2 \%$ of cases according to our analysis. We found a significantly higher diseasefree survival rate for colon cancer patients than rectal cancer patients: this was probably due to the relatively higher prevalence of local recurrence in the latter group. Despite these findings, overall survival was not different between the two subgroups of patients. Salvage abdominoperineal resection for recurrence following low anterior resection of the rectum was a feasible option with potentially curative results. In fact, if local recurrence is resectable, and is found in combination with resectable single-organ metastses (liver or lung) it should be treated by resection if morbidity is acceptable. Since distant metastases and local recurrence occur in 4,5\% of CRC patients and relapse can be prevented at least in part by radiotherapy, chemotherapy, or both, stage dependent adjuvant treatment has been recommended [31-33]. Adjuvant therapy for CRC increased the 5-year survival in randomized studies from $43 \%$ to $50 \%$ (without adjuvant therapy), to $63 \%$ to $70 \%$ (with adjuvant therapy) [31,32,34-36]. In our series, adjuvant treatment for T3N0 colon cancer patients failed to show any advantages in term of long-term overall survival. In fact, indications for adjuvant treatment in stage II colorectal cancer are somewhat little established [37]

Indications for adjuvant therapy are currently seen for colon-cancer $\mathrm{T}$ independent if the patient is affected by $\mathrm{N}$ positive locally advanced or $\mathrm{M}+$ disease.

Overall survival did not differ in our series for rectal-cancer patients who underwent preoperative vs. postoperative radiotherapy. In a recent review authors reported that preoperative radiotherapy improves local recurrence, overall mortality, but does not increase in sphincter sparing procedure rates [38]. However, the benefit of preoperative vs. postoperative radiotherapy remains unclear and debated. Hopefully, randomised controlled trials, which utilise these alternative clinical end points, will in future determine the precise percentages of the effect of different chemoradiation schedules on disease-free and overall survival for rectal cancer patients.

We found a correlation between perioperative blood transfusions and postoperative complication. This was probably due to the fact that patients transfused were at risk for their poor general conditions rather than for an independent effect of blood transfusion itself. We found no relationship between perioperative blood transfusions and long-term survival as reported by others [39].

The usefulness of postoperative surveillance programs has not been clarified yet. It seems likely that early detection of recurrence should improve patients' prognosis [40]. We adopted a uniform policy of follow-up over time with a growing use of PET scan over the last years when recurrence is suspected and the patient could benefit from radical resection of the recurrent disease. This is supported by other studies recently published $[41,42]$.

\section{Conclusion}

In conclusion, our study confirmed that surgery for colorectal cancer is safe (mortality <1\%). The main goals remain correct staging of tumour and R0 resection. Multivisceral resections result in morbidity and survival rates comparable to those for standard resections and neoadjuvant treatment in these cases may be necessary.

For patients with R0 resections, adjuvant treatment should be applied on the basis of common recommendations [30] , in special clinical situations (advanced disease, obstruction and/or perforation), and best of all in controlled studies. Despite all the potential and above-mentioned drawbacks of a follow-up and documentation system maintained for more than 10 years, we further conclude from our data that it is a useful tool for surgical quality control.

In addition, it provides a considerably valid institutional basis on which new clinical trials can be planned that will answer open questions about minimal-access-robotic assisted surgery, neoadjuvant treatment, multimodal therapy for colorectal cancer.

\section{Non-financial competing interests}

There are not competing interests (political, personal, religious, ideological, academic, intellectual, commercial or any other) to declare in relation to this manuscript.

\section{Authors' contributions \\ BA: Assisted in the format and design of the paper \\ AC: Critical review and design of the paper}

EB: Data analysis

MB, F O: Radiologists

RO: Radiotherapist

MGZ, NF: Oncologists

MV: Anaesthesiologist

AS: Histopathology evaluation

All authors read and approved the final manuscript 


\section{References}

I. Hermanek $\mathrm{P}$, Sobin $\mathrm{CH}$, editors: TNM classification of malignant tumours. In 2nd rev 1992 4th edition. Budapest, Springer: 1993:52-55.

2. Hermanek $P$, Henson DE, Hutter RVP, Sobin $C H$, editors: TNM supplement 1993. Budapest, Springer; 1993:30-32. 122-124

3. Sobin LH, Wittekind CH, editors: TNM classification of malignant tumours. 5th edition. New York Wiley; 1997:66-69.

4. Beahrs OH, Henson DE, Hutter RVP, Kennedy BJ, editors: American Joint Committee on Cancer (AJCC) Manual for staging of cancer. 4th edition. Philadelphia, Lippincott; 1992:pp75-79.

5. Fleming ID, Cooper JS, Henson DE, Hutter RVP, Kennedy PJ, Murphy GP, Sullivan PO, Sobin LH, Yarbro JW, editors: American Joint Committee on Cancer (AJCC) Cancer staging manual. 5th edition. Philadelphia, LIPPINCOTT; 1997:83-68.

6. Hermanek $P$, Wittekind $C$ : Residual tumour ${ }^{\circledR}$ classification and prognosis. Sem Surg Oncol 1994, 10:12-20.

7. Newland RC, Dent OF, Chapuis PH, Bokey EC: Clinicopathologically diagnosed residual tumour after resection for colorectal cancer. A 20 years prospective study. Cancer 1993, 72:1536-1542.

8. Griffen FD, Knight CDSr, Whitaker JM, Knight CD Jr: The double stapling technique for low anterior resection. Results, modifications and observations. Ann Surg 1990, 2 I I:745-752.

9. Wittekind $\mathrm{CH}$, Wagner $\mathrm{H}$, editors: TNM Klassifikation maligner tumoren. 5th edition. Berlin, Springer; 1997:87-95.

10. Moertel CG, Fleming TR, Macdonalds JS, Haller DG, Laurie JA, Targen GM, Ungerleider JS, Emerson WA, Tomey DC, Click JH: Fluorouracil plus levamisole as effective adjuvant therapy after resection of stage III colon carcinoma: a final report. Ann Intern Med 1995, I 22:321-326.

I I. Machover D, Goldschmidt E, Challet P, Metzger G, Zittoun J, Marquet J, Vandenbulcke JM, Misset JL, Schwarrzenberg L, Fourtillan JB: Treatment of advanced colorectal and gastric carcinoma with 5 fluorouracil and high-dose folinic acid. J Clin Oncol 1986, 4:685-696

12. Fucci L, Pirrelli M, Caruso ML: Carcinoma and synchronous hyperplastic polyps of the large bowel. Pathologica 1994, 86:37I-375

13. Cali RL, Pitsch RM, Thorson AG, Watson P, Tapia P, Blatchford GJ, Christensen MA: Cumulative incidence of metachronous colorectal cancer. Dis Colon Rectum 1993, 36:388-393.

14. Tanaka H, Hiyama T, Hanai A, Fujimoto I: Second primary cancers following colon and cancer in Osaka, Japan. Jpn J Cancer Res 1991, 82: $1356-1365$.

I5. Schaaal JC, Mondino JC, Paris F, Piat JM, Jaeck D: Synchronous colorectal cancers. J Chir (Paris) I99I, I 28:476-480.

16. Smith RL, Bohl JK, McElearney ST, Friel CM, Barclay MM, Sawyer RG, Foley EF: Wound infection after elective colorectal resection. Ann Surg 2004, 239:599-605.

I7. Hermanek P Jr, Wiebelt H, Riedl S, Staimmer D, Hermanek P: Longterm results of surgical therapy of colon cancer. Results of the Colorectal Cancer Study Group. Chirurg 1994, 65:287-297.

18. Billingsley KG, Morris AM, Dominitz JA, Matthews B, Dobie S, Barlow W, Wright GE, Baldwin LM: Surgeon and hospital characteristics as predictors of major adverse outcomes following colon cancer surgery: understanding the volume-outcome relationship. Arch Surg 2007, I42:23-3I. discussion 32.

19. Bokey EL, Chapuis PH, Fung C, Hughes WJ, Koorey SG, Brewer D, Newland RC: Postoperative morbidity and mortality following resection of the colon and rectum for cancer. Dis Colon Rectum 1995, 38:480-486

20. McArdle CS, McMillan DC, Hole DJ: Impact of anastomotic leakage on long-term survival of patients undergoing curative resection for colorectal cancer. Br / Surg 2005, 92: I I50-I I 54.

21. Hermanek P, Wiebelt H, Staimmer D, Riedl S: Prognostic factors of rectum carcinoma: experience of the German Multicentre Study SGCRC. In Tumori Volume 8I. Issue 3 suppl German Study Group Colorectal Carcinoma; 1995:60-64

22. Konn M, Morita T, Hada R, Yamanka Y, Sasaki M, Munakata H, Suzuki $H$, Inoue $S$, Endoh $M$, Sugiyama $Y$ : Survival and recurrence after low anterior resection and abdominoperineal resection for rectal cancer: the results of a long-term study with a review of the literature. Surg Today 1993, 23:21-30.
23. Kierkegaard $O$, Olesen $B$ : [Prognosis of patients with rectal cancer treated in a department of general surgery]. Ugeskr Laeger I991, I 53:2182-2184.

24. Bethune WA: Carcinoma of the rectum: $\mathbf{5 0 8}$ patients with failure analysis and implication for adjuvant therapy. J Can Assoc Radiol 1987, 38:209-2|4.

25. Lopez MJ, Monafo WW: Role of extended resection in the initial treatment of locally advanced colorectal carcinoma. Surgery 1993, I | 3:365-372.

26. Rowe VL, Frost DB, Huang S: Extended resection for locally advanced colorectal carcinoma. Ann Surg Oncol 1997, 4: I 3 I- I 36.

27. Gebhardt C, Meyer W, Ruckriegel S, Meier U: Multivisceral resection of advanced colorectal carcinoma. Langenbecks Arch Surg 1999, 384:194-199.

28. Staniunas RJ, Schoetz DJ]: Extended resection for carcinoma of colon and rectum. Surg Clin North Am 1993, 73: I 17-129.

29. Izbicki JR, Hosch SB, Knoefel WT, Passlick B, Bloechle C, Broelsch $C E$ : Extended resections are beneficial for patients with locally advanced colorectal cancer. Dis Colon Rectum 1995, 38: $|25|-1256$

30. Turoldo A, Balani A, Tonello C, Ziza F, Roseano M: Extended resection in locally advanced colon cancer. Ann Ital Chir 1998, 69:639-644

3I. Link KH, Staib L, Kreuser ED, Beger HG: Adjuvant treatment of colon and rectal cancer: impact of chemotherapy, radiotherapy, and immunotherapy on routine postsurgical patient management: Forschungsgruppe Onkologie Gatrointestinaler Tumoren (FOGT) Recent Results. Cancer Res 1996, | 42:3 | |-352.

32. Macdonald JS: Adjuvant therapy of colon cancer. CA Cancer J Clin 1999, 49:202-204.

33. Junginger T, Hossfeld DK, Sauer R, Hermanek P: Adjuvant therapy in patients with colorectal cancer. Dt Aerztebl 1999, 96:A698.

34. Wolmark N, Rockette H, Fisher B, Wicherham DL, Redmond C, Fisher ER, Jones J, Mamounas EP, Ore L, Petrelli NJ, Spurr C, Dimitrov $\mathrm{N}$, Romond $\mathrm{EH}$, Sutherland CM, Kardinal CG, DeFusco PA, Jochimsen $P$ : The benefit of leucovorin-modulated fluorouracil as postoperative adjuvant therapy for primary colon cancer and bowel project protocol C-03. J Clin Oncol 1993, I I: | 879- | 887.

35. Francini G, Petrioli R, Lorenzini L, Mancini S, Armenio S, Tanzini G, Marsili S, Aquino G, Marzocca G, Civitelli S: Folinic and 5-fluorouracil as adjuvant chemotherapy in colon cancer. Gastroenterology 1994, I 06:899-906.

36. Zaniboni A, Labianca $R$, Marsoni S, Torri V Mosconi P, Grilli R, Apolone G, Cifani S, Tinazzi A: GIVIO-SITAC 0 I: a randomized trial of adjuvant 5-fluorouracil and folinic acid administered to patients with colon carcinoma-long term results and evaluation of the indicators of health-related quality of life; Gruppo Italiano Valutazione Interventi in Oncologia; Studio Italiano Terapia Adiuvante. Colon Cancer 1998, 82:2 I35-2I 44.

37. Wils J: Adjuvant treatment of colon cancer: past, present and future. J Chemother 2007, I 9: | |5-122.

38. Wong R, Tandan V, De Silva S, Figueredo A: Pre-operative radiotherapy and curative surgery for the management of localized rectal carcinoma. Cochrane Database Syst Rev 2007, 18:CD002I02.

39. Jagoditsch M, Pozgainer P, Klingler A, Tschmelitsch J: Impact of blood transfusions on recurrence and survival after rectal cancer surgery. Dis Colon Rectum 2006, 49: I I I6-I I 30.

40. Castells A, Bessa X, Daniels M, Ascaso C, Lacy AM, Garcia-Valdecasas JC, Gargallo L, Novell F, Astudillo E, Filella X, Pique JM: Value of postoperative surveillance after radical surgery for colorectal cancer: results of a cohort study. Dis Colon Rectum 1998, 4I:7|4-723.

4I. Fernandez FG, Drebin JA, Linehan DC, Dehdashti F, Siegel BA, Strasberg SM: Five-year survival after resection of hepatic metastases from colorectal cancer in patients screened by positron emission tomography with F-I 8 fluorodeoxyglucose (FDG-PET). Ann Surg 2004, 240:438-447.

42. Joyce DL, Wahl RL, Patel PV, Schulick RD, Gearhart SL, Choti MA: Preoperative positron emission tomography to evaluate potentially resectable hepatic colorectal metastases. Arch Surg 2006, 141:1220-1226 